\title{
Cellulolytic Bacteria Occurring in the Rumen of Sheep Conditioned to Low-protein Teff Hay
}

\author{
By BARBARA S. SHANE, L. GOUWS AND A. KISTNER \\ National Chemical Research Laboratory, South African Council for \\ Scientific and Industrial Research, Pretoria, South Africa
}

(Accepted for publication 18 October I968)

\begin{abstract}
SUMMARY
From a large number of cultures of cellulolytic bacteria isolated from rumen contents of sheep conditioned to low-protein teff hay through the use of both a selective medium containing finely ground cellulose as energy source and a less selective medium containing cellobiose, xylan and starch, thirty isolates, representing three morphological types, were selected for detailed characterization. Nineteen isolates of Gram-negative curved rods belonged to the genus Butyrivibrio. Of these one was identical with and ten closely related to $B$. fibrisolvens. The remaining eight Butyrivibrio cultures differed in several respects from the only other defined species within this genus, $B$. alactacidigens. Four coccal isolates were identified as Ruminococcus albus and five as $\boldsymbol{R}$. flavefaciens. Two strains of sporeformers belonged to the genus Clostridium but could not be identified with any of the cellulolytic species of this genus listed by Bergey's Manual.
\end{abstract}

\section{INTRODUCTION}

In a study of the carbohydrate and lactate-fermenting bacteria of the rumen of sheep conditioned to low-protein teff hay, Gilchrist \& Kistner (I962) found that the most abundant cellulose-digesting bacteria were generally Gram-negative curved rods which usually produced narrow zones of cellulolysis in thin cellulose agar films. Gramnegative and Gram-positive cocci were also present in small numbers in cultures inoculated with high dilutions of the samples.

The present paper gives a fuller description of the cellulolytic bacteria occurring in sheep conditioned to this diet and relates them to previously described species. The majority of the cultures studied were isolated from agar media which contained acidtreated, ball-milled cotton wool cellulose (Hungate, 1950) as sole energy source. However, in view of the report of Halliwell \& Bryant (1963) that this form of cellulose is an unsuitable substrate for some types of cellulolytic bacteria from the rumen, isolations were also made on a less selective medium containing cellobiose, xylan and starch. Of those isolates from this medium which were found to be cellulolytic, representative strains were included in the study.

\section{METHODS}

The methods used in the characterization of the isolates were similar to those described by Kistner (1960) and Kistner \& Gouws (1964). In the following, details will, therefore, only be given of amendments to the original procedures. 


\section{Media}

Cellobiose-xylan-starch medium. A medium of the same basal composition as the cellulose and cellobiose agar media, but containing $0.3 \%$. (w/v) of each of cellobiose, xylan and starch (CXS-agar) was prepared. This medium was used for counts, isolations and maintenance of isolates of a section of the bacterial population of the rumen which would include all the cellulolytic species but exclude non-cellulolytic, glucosefermenting species.

Media for fermentation tests. The clarified rumen fluid content of the basal medium was decreased from 30 to $20 \%(\mathrm{v} / \mathrm{v})$, the bicarbonate concentration was reduced to one-tenth of that used originally and the medium equilibrated with a gas mixture containing $10 \% \mathrm{CO}_{2}$. In this way the buffering capacity was drastically lowered so that even slight growth gave rise to measurable $\mathrm{pH}$ changes. The concentration of cotton wool and filter paper cellulose was diminished to $0.2 \%(\mathrm{w} / \mathrm{v})$, while the concentrations of the remaining carbon sources were retained at $0.5 \%(\mathrm{w} / \mathrm{v})$.

Medium for end-product determination. Only the cellobiose medium was used and this was dispensed in $50 \mathrm{ml}$. volumes into rubber-stoppered, $\mathrm{CO}_{2}$-purged, $6 \mathrm{oz}$. bottles.

Media for other tests. The media for the determination of temperature tolerance, carbon dioxide requirement, nitrate reduction, Voges-Proskauer reaction and gelatin. liquefaction were similar in composition to the counting medium, but contained $0.5 \%(\mathrm{w} / \mathrm{v})$ cellobiose. Bicarbonate was omitted from the carbon dioxide requirement test medium and it was equilibrated with oxygen-free nitrogen. The $\mathrm{pH}$ value was adjusted to 6.7 before sterilization. Potassium nitrate was added to the nitrate reduction test medium to give a final concentration of $0 . \mathrm{I} \%(\mathrm{w} / \mathrm{v})$; the gelatin liquefaction test medium contained $0.4 \%(w / v)$ gelatin and $\mathrm{I} \cdot 5 \%(\mathrm{w} / \mathrm{v})$ agar. The medium for determining $\mathrm{H}_{2} \mathrm{~S}$ production contained $0 . \mathrm{I} \%$ cellobiose and $0.05 \%(\mathrm{w} / \mathrm{v})$ ferric ammonium citrate.

Anaerobic phosphate buffer. This was modified to contain $0.025 \%$ instead of $0.05 \%$ $(\mathrm{w} / \mathrm{v})$ cysteine $\mathrm{HCl} \cdot \mathrm{H}_{2} \mathrm{O}$.

\section{Bacteriological procedures}

Isolations from CXS-agar. Isolations were also made from CXS-agar film cultures inoculated with the $10^{-7}$ and $10^{-8}$ dilutions of samples of strained rumen contents. Colonies from the primary cultures were immediately transferred to slopes of the same medium. Subsequently, the cultures were tested for cellulolytic activity and only those which possessed such activity were further purified, where necessary.

Determination of cell morphology, motility and flagellation. The water of syneresis of $17-24 \mathrm{hr}$ old cultures on rumen fluid agar slants containing $0.1 \%(w / v)$ glucose or cellobiose was used for these tests, as recommended by Bryant \& Small (1956). Fresh wet mounts of this material were examined without delay for motility and morphology. Gram reaction and cell dimensions were determined in Gram-stained smears of this material, while type of flagellation was determined by examination of smears stained according to Leifson (195I).

Further tests. The tests for production of acetylmethylcarbinol, indole and $\mathrm{H}_{2} \mathrm{~S}$ and the tests for nitrate reduction and gelatin liquefaction were carried out according to standard methods (Society of American Bacteriologists, 1957). 


\section{Determination of fermentation acids}

The acids were extracted from the deproteinized culture liquid by the method of Neish (1952), with the exception that excess of alkali was added to the receiver containing ether to prevent loss of the lower acids by evaporation. The excess of alkali was back-titrated and water evaporated off. The acids were liberated from their sodium salts and separated by column chromatography on silicic acid by the method of Ramsey (I963), but using, successively, benzene, chloroform, 5 and $8 \%(\mathrm{v} / \mathrm{v})$ tertiary butyl alcohol in chloroform as eluants. The effluent from the column was fractionated into $5 \mathrm{ml}$. fractions, each of which was titrated with $0.01 \mathrm{~N}$-alcoholic $\mathrm{KOH}$ solution.

\section{RESULTS}

\section{Isolation}

Seventy-eight cultures were isolated non-selectively from cellulose agar films inoculated with the $10^{-6}$ and $10^{-7}$ dilutions of samples of strained rumen contents obtained on different dates from six Merino wethers which had been fed low-protein teff hay for at least 4 weeks. Of these, 27 were lost on serial transfer in cellulose agar as the result of poor growth. A further 16 of the 98 cultures isolated from CXS-agar films inoculated with the $10^{-7}$ or $10^{-8}$ dilutions of samples from the same sheep were found to be cellulolytic according to the test of Bryant \& Burkey (1953a). Five of these were also lost on serial transfer in cellulose agar. The surviving cultures were examined for cell morphology, Gram reaction, motility, type of flagellation, the appearance of the colonies in cellobiose and cellulose agar films and the nature of the zones of cellulolysis surrounding the colonies in the latter medium.

\section{Characteristics of the isolates}

Three morphological types of cellulolytic bacteria were observed. In agreement with earlier findings (Gilchrist \& Kistner, 1962; Gouws \& Kistner, 1965), Gram-negative, curved rods were the most abundant cellulose-digesting bacteria in strained rumen fluid from sheep on this diet. The cells were $0.4-0.5 \mu$ in diameter by $\mathrm{I} \cdot 0-\mathrm{I} \cdot 8 \mu$ long, with tapered ends. One isolate was exceptional in that the mean dimensions of the cells were 0.7 by $2.7 \mu$. The cells occurred singly, in pairs and in short to long chains. With one exception, the isolates were found to be motile, though even in $17 \mathrm{hr}$ cultures the proportion of motile cells varied from test to test and was sometimes very low, especially in the chain-forming strains. The motile strains generally had single polar to subpolar flagella. However, in the case of those isolates which occurred mainly in long chains, it was difficult to determine the number of flagella per organism and the site of attachment. Surface colonies on cellobiose agar were generally tan-coloured, smooth, entire and flat to convex, while deep colonies in the same medium were spindle-shaped or Y-shaped. The zones of cellulolysis in cellulose agar films were narrow and often indistinct.

Second in abundance were Gram-negative, Gram-variable and Gram-positive cocci, the diameters of which varied between 0.6 and $0.9 \mu$. The cells occurred singly, in pairs and, in the case of some isolates, in chains of variable length. Most of the isolates produced capsules. Colonies of the cocci on cellobiose agar were circular, spindle-shaped or punctiform, smooth, opaque, butyrous, with entire margins and 
flat to convex in elevation. The colonies in cellulose agar films mostly remained small, even after extended incubation, and the zones of cellulolysis were narrow and indistinct. However, two isolates gave rise to rhizoid colonies surrounded by fairly wide, distinct clearings. Two isolates produced yellow pigment when grown in cellulose agar.

Gram-negative, motile rods $2 \cdot 4-3.0 \mu$ long by $0.6-0.7 \mu$ in diameter, with peritrichous arrangement of flagella, occurred in high numbers in rumen contents of two of the sheep on two sampling days. Old cells of these rods showed single, terminal to subterminal oval spores $\mathrm{I} \cdot 3-\mathrm{I} \cdot 6 \mu$ long by $0.5-0.8 \mu$ in diameter, in swollen sporangia. Surface colonies on cellobiose agar films were punctiform to circular, sometimes rhizoid, smooth, opaque, butyrous, flat to convex, with entire margins. The colonies in cellulose agar films were small and irregularly shaped, surrounded by large transparent zones which were sharply demarcated from the background of undigested cellulose.

On the results of the preliminary tests, twenty-five newly isolated cultures were selected for more detailed characterization. In the case of the curved rods and the cocci, the isolates were selected to include a wide range of combinations of cell dimensions, Gram-reaction, chain formation, pigment production and appearance of the zones of cellulolysis. Since the isolates of sporeformers were very uniform in their morphological characteristics, only two cultures were included in the selection. To the newly isolated cultures were added four isolates of cellulolytic curved rods and one of a pigment-producing coccus obtained I-2 years previously from four sheep which had been fed a similar batch of low-protein teff hay. Details of the origin of the selected isolates are shown in Table I. The morphological, cultural and biochemical characteristics determined for the curved rods and sporeformers are presented in Table 2 and those of the cocci in Table 3.

Curved rods. The 19 isolates studied were generally similar in Gram reaction, morphology, motility, type of flagellation and in the size of the zones of clearing in cellulose agar. Few strains grew at $22^{\circ}$, most at $30^{\circ}$ and $45^{\circ}$ and all at $37^{\circ}$. Ten strains grew without $\mathrm{CO}_{2}$, none produced acetylmethylcarbinol or indole, none reduced nitrate and only one produced $\mathrm{H}_{2} \mathrm{~S}$. Unlike the non-cellulolytic Butyrivibrio species isolated on a casein-containing medium by Blackburn \& Hobson (1962), most of our cultures of curved rods did not liquefy gelatin. The carbon sources L-arabinose, galactose, sucrose, cellobiose, pectin, starch and xylan were fermented by all the isolates of curved rods, while none fermented L-rhamnose, glycerol, mannitol, inositol or sodium lactate. The isolates differed in the utilization of the remaining carbon sources listed in Table 2. Although all cultures had produced zones of clearing in cellulose agar films, only four produced visually detectable solubilization of cotton wool and filter paper cellulose in liquid medium. All 19 isolates produced formate, butyrate, hydrogen and at least traces of ethanol in the fermentation of cellobiose in rumen fluid-containing medium. One group produced appreciable amounts of lactate and removed acetate from the medium during cellobiose fermentation, while a second group produced acetate but little or no lactate. These differences in fermentation patterns correlated well with differences in the nutritional requirements of the isolates, the acetate-producing cultures being more fastidious (Shane, I966). It therefore seemed justifiable to subdivide the curved rods ino groups $I$ and 2, as shown in Table 2. The characteristics of isolates CE 52 and CE 74 were on the borderline between groups I and 2, both neither producing nor utilizing appreciable amounts of acetate, 
though the fairly large concentrations of lactate produced seemed to indicate that they were more closely related to group I strains. However, isolate CE 74 was later moved to group 2 when its nutritional requirements were found to fit in more closely with this group.

Table I. Origins of isolates of cellulolytic rods and cocci

\begin{tabular}{|c|c|c|c|}
\hline Isolate* & Sheep no. & $\begin{array}{c}\text { Days on } \\
\text { diet }\end{array}$ & $\begin{array}{l}\text { Sample } \\
\text { dilution }\end{array}$ \\
\hline \multicolumn{4}{|c|}{ Curved rods, Group I } \\
\hline CE 36 & $\mathrm{~K}$ io & $4 \mathrm{I}$ & $10^{-7}$ \\
\hline CE 46 & $\mathbf{K}$ io & $6 I$ & $10^{-6}$ \\
\hline CE 47 & $\mathrm{~K}$ I0 & 61 & $10^{-6}$ \\
\hline CE $5 \mathrm{I}$ & $\mathbf{K}_{3}$ & 68 & $10^{-6}$ \\
\hline CE 52 & $\mathrm{~K}_{3}$ & 68 & $10^{-6}$ \\
\hline CE 53 & $\mathrm{~K}_{3}$ & 68 & $10^{-6}$ \\
\hline CE 56 & $\mathrm{~K}_{3}$ & 68 & $10^{-8}$ \\
\hline CE 58 & $\mathrm{~K} 10$ & 68 & $10^{-6}$ \\
\hline CXs 13 & $\mathrm{~K}$ I0 & 40 & $10^{-7}$ \\
\hline Cxs 18 & K 10 & 40 & $10^{-7}$ \\
\hline 7 & $\mathbf{R}_{3}$ & 33 & $10^{-7}$ \\
\hline \multicolumn{4}{|c|}{ Curved rods, Group 2} \\
\hline CE 64 & K 33 & 28 & $10^{-7}$ \\
\hline CE 65 & K 33 & 55 & $10^{-7}$ \\
\hline CE $6 \overline{6}$ & K 33 & 55 & $10^{-6}$ \\
\hline CE 74 & K 23 & 55 & $10^{-7}$ \\
\hline CE 78 & K 23 & 55 & $10^{-6}$ \\
\hline $6 \mathrm{~B}$ & K I0 & 28 & $10^{-8}$ \\
\hline 6D & K 20 & 49 & $10^{-6}$ \\
\hline $7 \mathrm{~A}$ & $\mathrm{~K}$ I3 & $2 \mathrm{I}$ & $10^{-7}$ \\
\hline \multicolumn{4}{|c|}{ Sporeformers } \\
\hline CE 3 & $\mathbf{K}_{2}$ & $4 I$ & $10^{-7}$ \\
\hline CE 30 & $\mathbf{K}_{3}$ & $4 \mathrm{I}$ & $10^{-7}$ \\
\hline \multicolumn{4}{|c|}{ Cocci, Group I } \\
\hline CE 54 & $\mathbf{K}_{3}$ & 68 & $10^{-8}$ \\
\hline CE 63 & K 23 & 28 & $10^{-7}$ \\
\hline $\operatorname{cxs} 60$ & K 23 & 55 & $10^{-8}$ \\
\hline $\operatorname{cxs} 65$ & K 23 & 55 & $10^{-8}$ \\
\hline \multicolumn{4}{|c|}{ Cocci, Group 2} \\
\hline CE 70 & K 33 & 55 & $10^{-6}$ \\
\hline CE 77 & K 23 & 55 & $10^{-6}$ \\
\hline $\operatorname{cxs} 36$ & $\mathrm{~K}_{3}$ & 46 & $10^{-8}$ \\
\hline $\operatorname{cxs} 67$ & K 23 & 55 & $10^{-8}$ \\
\hline $4 \mathrm{~A}$ & $R_{3}$ & 29 & $10^{-4}$ \\
\hline
\end{tabular}

* Code numbers with prefix ' CXS' indicate isolates from cellobiose-xylan-starch agar films. The remaining isolates were obtained from cellulose agar.

Isolates 7, 6 D, $4 \mathrm{~A}$ were isolated in $1961: 6 \mathrm{~B}, 7 \mathrm{~A}$ in 1962 : all the rest in 1963.

Cocci. The group of coccal isolates chosen for further characterization was comprised of Gram-negative, Gram-variable and Gram-positive cultures. It included cultures in which the cells occurred in short or long chains. The nine isolates had the following characteristics in common: growth at $37^{\circ}$, no growth at $22^{\circ}$; no growth in the absence of $\mathrm{CO}_{2}$; no production of $\mathrm{H}_{2} \mathrm{~S}$ or indole; nitrate not reduced, gelatin not liquefied; cellobiose and xylan fermented and either cotton wool or filter paper cellulose visibly solubilized; L-arabinose, L-rhamnose, D-xylose, trehalose, glycerol, mannitol, inositol, salicin, aesculin, sodium lactate, inulin and starch not utilized; 


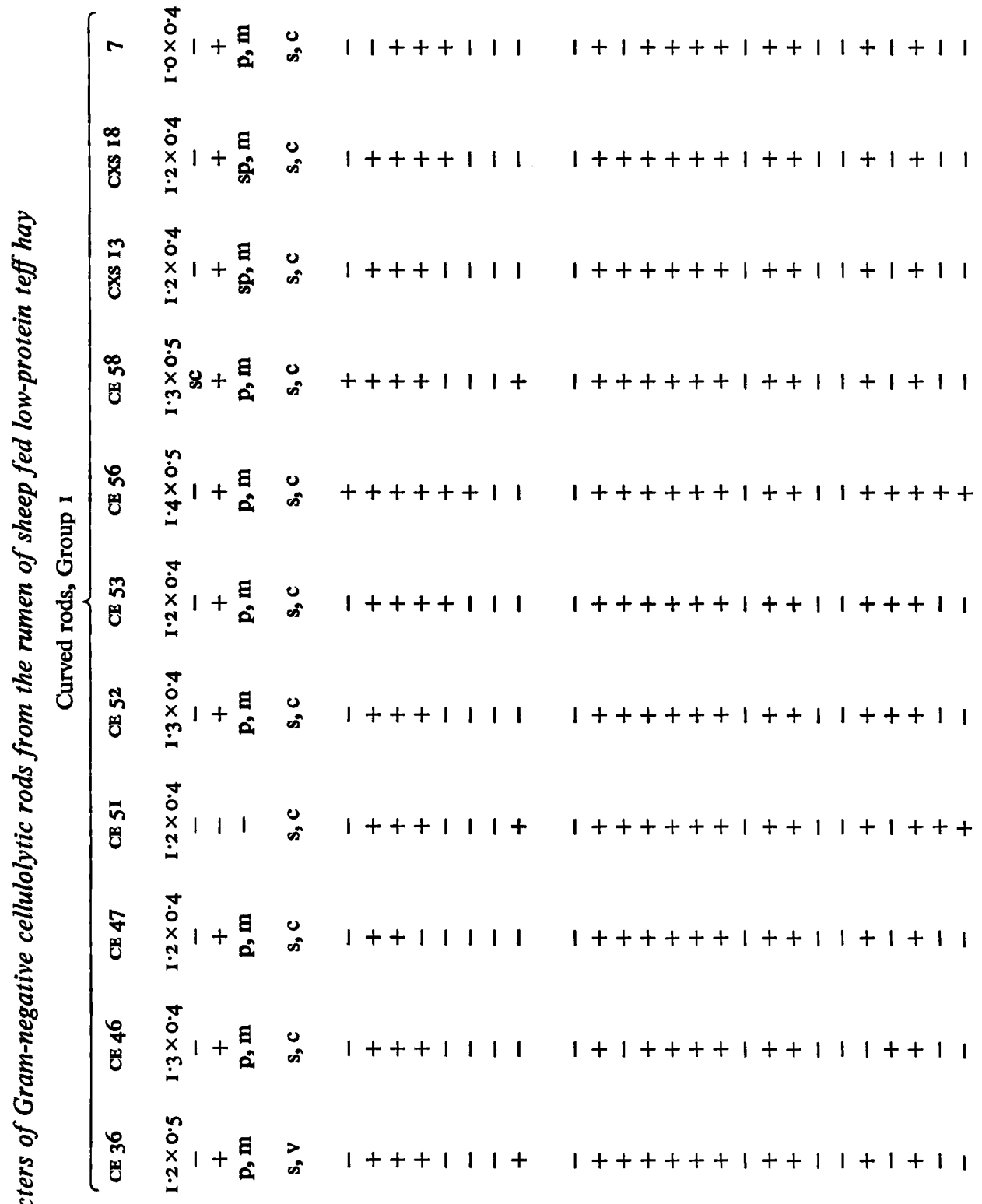

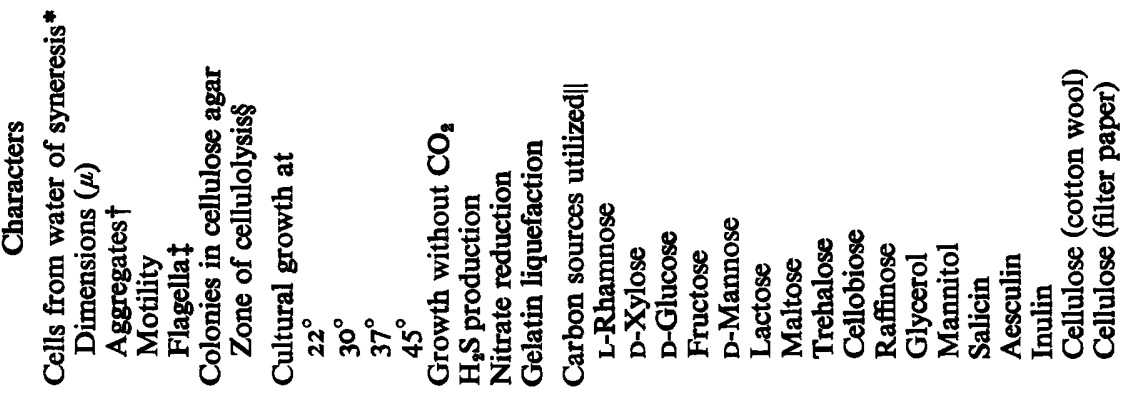




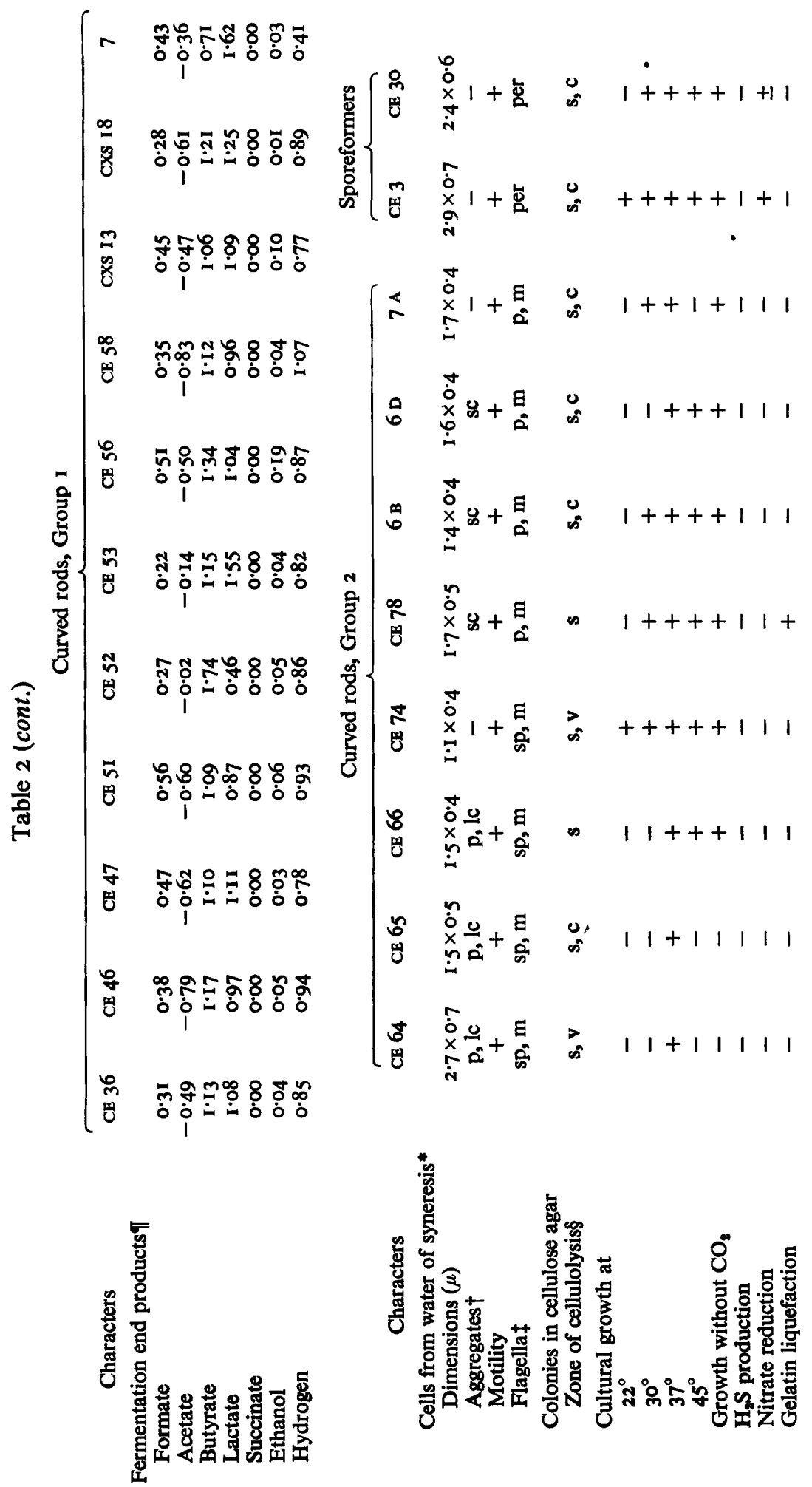




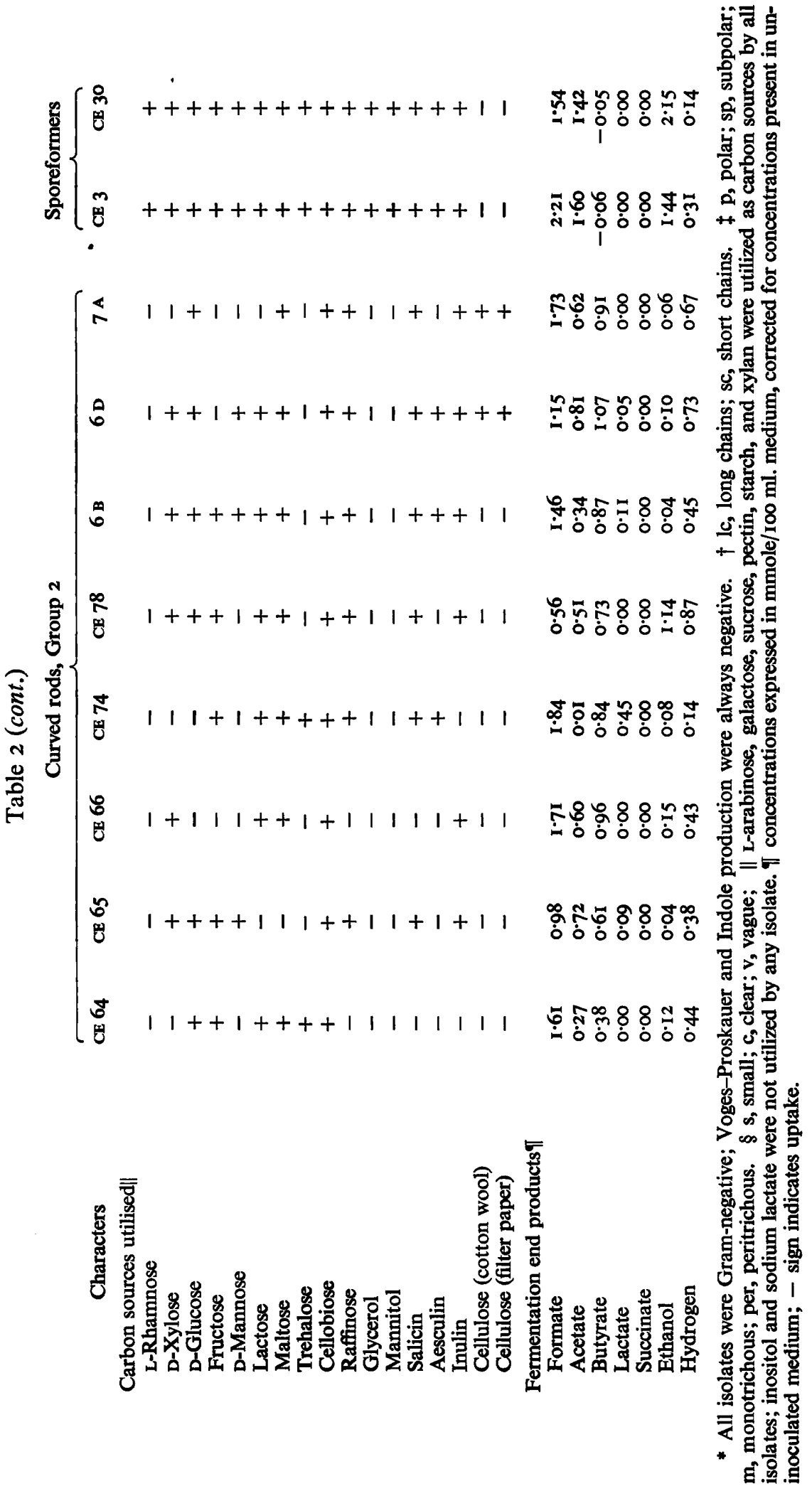


large amounts of formate and acetate produced in the fermentation of cellobiose. A good correlation was found between production of large amounts of ethanol and lack of production of succinate by isolates CE 54, CE 63, CXs 60 and CXs 65 . With the exception of isolate CE 54, cells of these cultures did not occur in chains. In the chainforming isolates $\mathrm{CE} 70, \mathrm{CE} 77$, CXS 36, cXs 67 and $4 \mathrm{~A}$ the production of large amounts of succinate correlated well with the production of only traces of ethanol. Accordingly, the coccal isolates were divided into groups $I$ and 2 in Table 3.

Sporeformers. The two cultures of sporeformers, CE 3 and CE 30, which were isolated from different sheep, were similar in all characteristics, except growth at $22^{\circ}$. Both grew at temperatures between $30^{\circ}$ and $45^{\circ}$ and required no $\mathrm{CO}_{2}$ for growth. Neither produced acetylmethylcarbinol, $\mathrm{H}_{2} \mathrm{~S}$ or indole, reduced nitrate or liquefied gelatine. Of the carbon sources tested, only inositol and sodium lactate were not utilized. In spite of the fact that the sporeformers had produced extensive clearings in cellulose agar films, neither cotton wool nor filter papercellulose were visibly solubilized in a liquid medium. The sporeformers produced large quantities of formate, acetate and ethanol and lesser amounts of hydrogen in the fermentation of cellobiose. Butyrate, lactate and succinate were not produced.

\section{DISCUSSION}

In so far as they are anaerobic, non-sporeforming, monotrichous, Gram-negative, curved rods that ferment carbohydrates with the production of large amounts of butyric acid, 18 of the 19 isolates of curved rods studied here doubtlessly belong to the genus Butyrivibrio (Bryant \& Small, I956). In the case of isolate CE 5I, neither motility nor occurrence of flagella were demonstrated. Nevertheless, in view of general similarity of this isolate to other members of Group I, it seems justifiable to regard CE $5 \mathrm{I}$ as a member of the genus. A similar view was taken by Margherita \& Hungate (1963) of a culture for which motility and presence of flagella could not be demonstrated, but which otherwise agreed with the description of the species $B$. fibrisolvens. With the exception of culture CE 64, the cells of our isolates are rather smaller than those of the strains described by Bryant \& Small (1956), but similar in size to those described by Blackburn \& Hobson (I962) and Van Gylswyk (I968).

Within the genus Butyrivibrio, Bryant \& Small defined only a single species, viz. $B$. fibrisolvens. The characteristics of 17 of the 48 isolates studied in some detail by these workers did not fit the description of $B$. fibrisolvens and the isolates differed so much amongst themselves, that no further species were defined. More recently, Hungate (1966) has proposed a second species, B. alactacidigens, to accommodate those strains which do not produce lactic acid in the fermentation of carbohydrate.

Of the lactate-producing isolates listed in group I of Table 2, the characteristics of culture CE 53, only, fall within the definitions of Butyrivibrio fibrisolvens (Bryant \& Small, 1956), provided the differences in cell dimensions are ignored. The other members of our Group I may be regarded as closely related variants of this species. The characteristics in which they differ from $B$. fibrisolvens are: possible absethce of flagella and lack of motility (strain CE 5I); growth at $22^{\circ}$ (strains CE 56 and CE 58); no growth at $45^{\circ}$ (CE 47); failure to grow in the absence of $\mathrm{CO}_{2}$ (CE 36, CE 46, CE 47, CE 5I, CE 52, CE 58, CXS 13); inability to utilize glucose (CE 46, 7); inability to utilize salicin (CE 46); and inability to utilize aesculin (CE 36, CE 47, CE 5 I, CE 58, CXS 13, CXS 18, 7). 
The acetate-producing isolates listed under Group 2 in Table 2 differ more from one another than the acetate-utilizing isolates of group 1 . None of the former could be identified with Butyrivibrio alactacidigens (Hungate, 1966). Isolate $6 \mathrm{~B}$ was most closely related to this species, differing from it in fermenting D-xylose, solubilizing cellulose (though not visibly in liquid medium) and not fermenting L-rhamnose. The other members of group 2 differed from $B$. alactacidigens in six to eight characters.

The results presented in Table 2 seem to suggest that the good correlations between acetate utilization, 'high lactate' and 'low formate' on the one hand, and between acetate production, 'low lactate' and 'high formate' on the other hand would possibly provide a better basis for dividing the genus Butyrivibrio into species than the scheme based mainly on production or lack of production of lactic acid. A detailed study, with standardized methods, of a large number of Butyrivibrio isolates obtained from different habitats and different geographic locations, followed by estimation of the degree of similarity between the isolates, could help much to resolve the present unsatisfactory taxonomic state of the genus Butyrivibrio. An investigation along these lines, albeit of a more limited scope, for Ruminococcus isolates from the rumen of sheep on three different diets was described by Jarvis \& Annison (1967).

The coccal isolates listed in Table 3 all belong to the genus Ruminococcus (Sijpesteijn, I95I), as redefined by Hungate (I957), Bryant, Small, Bouma \& Robinson (I958) and Hungate (1966). The characteristics of the four strains classed under Group I fall within the definitions of the species $R$. albus (Hungate, 1957), as amended by Bryant et al. (1958) and Hungate (1966), with the minor exception that strains cxs 60 and CXs 65 showed growth at $45^{\circ}$. Isolates CE 70, CXs $36, \mathrm{CXs} 67$ and 4 belong to the species $R$. flavefaciens, as redefined by Hungate (1966). Isolate CE 77 is closely related to this species but differs from it in being able to ferment a larger variety of carbohydrates. This also holds for one of the strains studied by Dehority (1962).

By virtue of their morphological characteristics and requirement for anaerobic conditions for growth, the sporeformers belong to the genus Clostridium. However, they differ in many respects from the cellulolytic sporeformers $C$. cellobioparus (Hungate, 1944), C. lochheadii and C. longisporum (Hungate, 1957) previously isolated from the rumen. Moreover, they could not be identified with any of the cellulolytic Clostridium species listed in Bergey's Manual (1957). In view of their sporadic occurrence in high dilutions of rumen contents from only two sheep on low-protein teff hay, they are probably of minor significance in cellulose digestion in the rumen. Clostridium lochheadii and C. longisporum, likewise, occurred only sporadically in high numbers in rumen contents of cows fed different combinations of timothy hay, salt and concentrates (Hungate, 1957).

It should be noted that the isolates obtained from CXS-agar films belonged to the same groups as those obtained from cellulose agar films. Bacteroides succinogenes which has been reported as one of the more abundant cellulolytic bacteria in rumen contents of cattle on different diets, including low-protein wheat straw (Hungate, 1950; Bryant \& Burkey, 1953b) was not found among the isolates. Even though the cotton wool cellulose used in our media for direct cellulolytic counts and isolations could have been a physically unsuitable substrate for growth of this organism, it should have been able to utilize the cellobiose in the CXS-agar and therefore have shown up among the isolates from this medium, had it been present in high numbers in the samples. 
Though Table I presents information on the origin of only those isolates which were studied in detail, it is evident that morphologically and physiologically similar strains of butyrivibrios and ruminococci were isolated from the same sheep on different sampling dates and also simultaneously from different sheep. On the other hand, different species of the same genus occurred in the same sample of rumen contents. The four Butyrivibrio cultures and one $R$. flavefaciens strain which had been isolated I-2 years previously from sheep conditioned to low-protein teff hay, did not differ more from the newly isolated members of their respective groups than these amongst themselves. Thus, although a particular strain of a functional rumen micro-organism may disappear from the rumen in a matter of months, as is suggested by the serological studies of Margherita \& Hungate (1963), it is probably replaced by physiologically similar strains.

The fact that a greater diversity of cellulose-digesting bacterial species normally occurs in the rumen contents from sheep conditioned to low-protein teff hay than in rumen contents of sheep conditioned to lucerne hay, suggests that in the former habitat environmental conditions do not favour the selection of a particular species to the same extent as in the latter. The degree to which the nutritional requirements of the various species are met by the environment probably plays a major rôle in the establishment of a balance between competing species. As a preliminary step in examining such relationships, a subsequent paper will deal with studies of some nutritional requirements of different species of cellulolytic bacteria.

The authors wish to thank The Chief, Veterinary Research Institute, Onderstepoort, for facilities for carrying out this work. Appreciation is also expressed to Dr F. M. C. Gilchrist and Dr H. M. Schwartz for constructive criticism and to Miss W. Jansen van Ryssen and Mr W. A. Dodds for able technical assistance.

This paper forms Part V of a series on 'Bacteria of the ovine rumen'; for parts I, II and IV see J. agric. Sci. 59, 77, 85 (1962) and 64, 5I (1965); for Part III see J. gen. Microbiol. 34, 447 (1964).

\section{REFERENCES}

Blackburn, T. H. \& Hobson, P. N. (1962). Further studies on the isolation of proteolytic bacteria from the sheep rumen. J. gen. Microbiol. 29, 69.

Bergey's Manual of Determinative Bacteriology, 7 th ed. Ed. by R. S. Breed, E. G. D. Murray \& N. R. Smith, (1957). London: Baillière, Tindal and Cox Ltd.

Bryant, M. P. \& BURKey, L. A. (I953a). Cultural methods and some characteristics of some of the more numerous groups of bacteria in the bovine rumen. J. Dairy Sci. 36, 205.

BRYANT, M. P. \& BURKEY, L. A. (1953b). Numbers and some predominant groups of bacteria in the rumen of cows fed different rations. J. Dairy Sci. 36, 218.

Bryant, M. P. \& SMall, N. (1956). The anaerobic monotrichous butyric acid-producing curved rodshaped bacteria of the rumen. J. Bact. 72, I6.

Bryant, M. P., Small, N., Bouma, C. \& Robinson, I. M. (I958). Characteristics of ruminal anaerobic cellulolytic cocci and Cillobacterium cellulosolvens n.sp. J. Bact. 76, 529.

Dehorrty, B. A. (1962). Isolation and characterization of several cellulolytic bacteria from in vitro rumen fermentations. J. Dairy Sci. 46, 217.

GIICHRIST, F. M. C. \& KISTNER, A. (I962). Bacteria of the ovine rumen I. The composition of the population on a diet of poor teff hay. J. agric. Sci. 59, 77.

Gouws, L. \& KistneR, A. (1965). Bacteria of the ovine rumen IV. Effect of change of diet on the predominant type of cellulose-digesting bacteria. J. agric. Sci. 64, $5 \mathrm{I}$. 
Halliwell, G. \& Bryant, M. P. (1963). The cellulolytic activity of pure strains of bacteria from the rumen of cattle. J. gen. Microbiol. 32, 441 .

Hungate, R. E. (1944). Studies on cellulose fermentation. I. The culture and physiology of an anaerobic cellulose-digesting bacterium. J. Bact. 48, 489.

Hungate, R. E. (1950). The anaerobic mesophilic cellulolytic bacteria. Bact. Rev. 14, I.

HuNGATE, R. E. (1957). Micro-organisms in the rumen of cattle fed a constant ration. Can. J. Microbiol. 3, 289.

Hungate, R. E. (1966). The Rumen and its Microbes, Ist ed. New York and London: Academic Press.

JARVIS, B. D. W. \& ANNISON, E. F. (1967). Isolation, classification and nutritional requirements of cellulolytic cocci in the sheep rumen. J. gen. Microbiol. 47, 295.

KisTNER, A. (1960). An improved method for viable counts of bacteria of the ovine rumen which ferment carbohydrates. J. gen. Microbiol. $23,565$.

KISTNER, A. \& Gouws, L. (1964). Cellulolytic cocci occurring in the rumen of sheep conditioned to lucerne hay. J. gen. Microbiol. 34, 447.

LEIrSON, E. (I95I). Staining, shape and arrangement of bacterial flagella. J. Bact. 62, 377.

MARgherita, S. S. \& Hungate, R. E. (1963). Serological analysis of Butyrivibrio from the bovine rumen. J. Bact. 86, 855 .

Neish, A.C. (1952). Analytical methods for bacterial fermentations, 2nd revision. Saskatoon, Nat. Research Council of Canada, Report No. 46-8-3.

Ramsey, H. A. (1963). Separation of organic acids in blood by partition chromatography. J. Dairy Sci. 46, 480.

SHANE, B.S. (1966). The predominant cellulolytic rumen bacteria of sheep fed low-protein teff hay. Ph.D. thesis, University of Witwatersrand.

SiJPESTEIJN, A. K. (I95I). On Ruminococcus flavefaciens, a cellulose-decomposing bacterium from the rumen of sheep and cattle. J. gen. Microbiol. 5, 869.

SOCIETY OF AMERICAN BACTERIOLOGISTS (1957). Manual of Microbiological Methods. New York, Toronto, London: McGraw-Hill Book Company, Inc.

VAN GyLSWYK, N. O. (1968). The cellulolytic rumen bacteria of sheep fed supplemented hay diets. M.Sc. thesis, University of Pretoria. 